\title{
BMA-sponsored candidates
}

The BMA sponsored 50 candidates for all the places to be held by elected members on the new GMC. Nominations were invited from BMA divisions and craft committees (through the GMS Committee from LMCs), and from any group of 10 BMA members; 126 nominations were received and the 50 candidates were elected, on a single (postal) transferable vote system, by the Representative Body. The new GMC, which takes office on 27 September, will have a majority of elected members-39 from England, six from Scotland, three from Wales, and two from Northern Ireland.

The postal election will be held between 4 fuly and 1 August.

The election addresses of the BMA-sponsored candidates are published here. Their present professional occupation, area of practice, basic qualifications, qualifying date, and (where appropriate) one higher qualification, are also given. Next week we will publish the names of other candidates among the total of 177 who are BMA members.

\section{England}

Dr H W Ashworth

As a founder of the first GP teaching health centre and with 25 years' teaching experience I am interested in the GMC's responsibility for maintaining education standards. I would encourage continuing experiments in undergraduate curricular arrangements and at postgraduate level I am concerned at the poor training in many junior hospital appointments. I support medical audit in all branches. I am concerned about manpower, and the medical disadvantages of many urban areas. I believe in the highest ethical standards and the GMC disciplinary code should be firm but not harsh. I am dissatisfied with the "three wise men" procedure. (General practitioner, Manchester; MB, ChB, 1944; MD.)

Dr C E Astley I qualified in Leeds and had six years war Dr C E Astley service in the RAF. In 1950 I was appointed consultant physician to the Teesside hospitals. For several years I was chairman of the Teesside Consultants Committee, then chairman of the Newcastle RCHMS. I have served on the CCHMS since 1966 and was chairman 1971-5. I am a member of the BMA Council and the JCC. I welcome the GMC reforms. Only the BMA speaks for all doctors and it is essential that its views are properly represented. If elected I will do all I can to see that these reforms work effectively while safeguarding the best interests of our profession. (Consultant physician and neurologist, Teesside; MB, ChB, 1939; FRCP.)

\section{Mr D E Bolt The profession's representatives on the new} GMC must understand the problems of their colleagues in practice. I qualified at a provincial medical school, served in general and hospital practice, and struggled up the consultant ladder in the difficult years 1950 to 1960. As a consultant general surgeon in a peripheral hospital (West Middlesex), I have experience of coping with unlimited demand despite inadequate resources. As Chairman of the Negotiating Subcommittee of CCHMS, I meet colleagues all round the country and learn about their problems, acquiring an insight which should allow me to make a useful contribution in the new GMC. (Consultant surgeon, Isleworth; MB, ChB, 1945; FRCS.)
Mr R Brearley $\begin{aligned} & \text { Education is the GMC's most important } \\ & \text { responsibility. Only through high }\end{aligned}$ standards can the public be guaranteed the quality of service which it deserves. Our public standing and professional satisfaction depend on it. In future the GMC's responsibility will extend into all phases of education. Regional hospital consultants and clinical tutors, and I am both, play an important role in postgraduate training; their experience should be available to the GMC. I have served on several local, national, and European professional committees; my experience of training and of Europe, where educational improvement is making great strides, would be of value to the new GMC. (Consultant surgeon, Liverpool; MB, ChB, 1945; ChM.)

Dr M M Burrows The new and enlarged GMC will take on an extra role in September. It will be concerned with the physical and mental health of doctors and its effect on patients. I welcome this, but care is required to maintain fairness to the individual doctor and proper protection for the public. The profession must continue to regulate itself and, what is more important, be seen by the general public to do so. I hope that this election will ensure an elected group of doctors with experience of professional problems at local and national level. (Consultant anaesthetist, Liverpool; $\mathrm{MB}, \mathrm{BCh}$, 1949; FFARCS.)

Dr A Elliott I look forward to the challenge of the new
GMC and if elected will do my best to uphold the profession's best traditions.

I am 58 and have practised in Ilford for over 30 years during which time I have striven as a representative of my colleagues for better remuneration and conditions of work. Apart from my BMA work I am on my LMC, have chaired my FPC, and am vice-chairman of the Society of FPCs. I sit on the GMSC, chair its Practice Organisation Subcommittee, and have been course organiser of the Ilford Vocational Training Scheme since 1971. (General practitioner, Ilford; MB, BCh, 1944; FRCGP.)

Dr J Fry The new GMC offers opportunities to meet the importance are the promotion of education for general practice and issues related to conditions and standards. To achieve improvements general practice must have a strong representation of experienced, sensitive, and sensible practitioners. There have never been more than four GPs on any council. As an elected member since 1970 and then as the senior treasurer of the GMC I have acquired some experience in its work. I invite my colleagues to allow me to continue to serve them. (General practitioner, Beckenham; MB, BS, 1944; FRCGP.)

Mr M J Gilkes From my earliest days as a medical student I held the GMC in great respect as a body
representing the highest standards. It was, therefore, with very considerable dismay that in company with so many other doctors I became aware that, it had, at least in some respects, allowed expediency to usurp its aims and deflect its purpose.

I find myself greatly reassured by the progress which has already been made in reforming its structure and activities and 
would like to have the opportunity to assist with the continuing restoration of its status and repute. (Consultant ophthalmologist, Brighton; MB, BS, 1946; FRCS.) Mr A H Grabham Having been actively involved in the the GMC, I have a special interest and responsibility in ensuring that the new GMC is a success. As chairman of the CCHMS I hope I will be able to contribute my experience in medicopolitical field, together with some knowledge of the problems and attitudes of consultants as a whole. My main interests would be in the care of the "sick doctor" through the proper development of the new health committee structure, together with the hope that the problems of overseas doctors might receive urgent and sympathetic attention. (Consultant surgeon, Kettering; MB, BS, 1953; FRCS.)

\section{Mr R K Greenwood}

During the last decade morale has fallen and good will been exploited beyond the limit. Concurrently there has been a significant increase in bureaucratic and multidisciplinary committees' involvement which has eroded the confidential doctor/patient relationship. In contrast clinical staff and facilities have been curtailed, inadequacies of the Health Service concealed, and complaints concerning medical care positively encouraged. Unity within the profession is essential. It is my aim to defend and promote this in order to protect the patient. (Consultant surgeon, Leicester; MB, BChir, 1952; MChir.)

\section{Dr G Hammad Full credit for the revolutionary changes} in the GMC must go to the BMA and other voices. Indeed, their patient fight has been supported by most doctors. Now both junior and overseas doctors will have a fair chance of being on the council and their views heard. One central computerised register for use by the BMA, DHSS, and GMC is required. A GMC public relations officer is needed to persuade public and profession that the GMC is not a court but "a professional independent medical organisation keeping both public interest and doctors' interests in balance." (Registrar in psychiatry, Norwich; MB, BCh, 1964.)

Dr J S Happel I was an elected member of the GMC BMA's GMC Working Group which prepared evidence to the Merrison Committee and assisted the passage of the Medical Act. As a past chairman of the BMA's Central Ethical Committee I have experience of advising doctors in trouble. I support high standards but the sick doctor should be shown sympathy. Overseas doctors must be given a fair deal and in undergraduate education there should be a swing to teaching basic practical skills. The new GMC is too large and if elected I would aim to cut costs. (General practitioner, Alresford; MB, ChB, 1947; FRCGP.)

Dr D F Heath I have been a Birmingham general practitioner for 35 years and became concerned in medicopolitics when secretary of the BMA's Birmingham Division for 15 years. I have been a member of the GMSC since 1959, and am a Fellow of the BMA. If elected I will do my best to uphold the prestige of family doctors and press for more basic training in medical schools to fit students for general practice. (General practitioner, Birmingham; MRCS, LRCP, 1934.)

\section{Dr J Stuart Horner My five years as chairman of a major} BMA committee have given me valuable medicopolitical experience which will assist an elected GMC to fulfil its wider role. The profession must have its own community medicine representatives on the new council if provision is being made for chief medical officers from all four Departments to be included. Action concerning the sick doctor requires care and compassion, and medical personnel responsibilities have given me unique experience of the problems. I am a committed Christian and my major interests include ethical problems in modern medicine, medical manpower planning, and medical education. (Area medical officer, Croydon; MB, ChB, 1956; FFCM.)

Dr M Hamid Husain I would like to ensure that the GMC, while protecting the public's interests, does not overlook those of doctors. It must safeguard the position of those doctors who are found to be unfit to practise on account of illness and should issue clear ethical guidance commensurate with presentday standards. Being of overseas origin would enable me to look upon the special problems of overseas doctors with sensitivity and understanding. Wide experience of professional committee work at local, regional, and national level, including the GMSC, would allow me to function effectively on the council. (General practitioner, Rotherham; MB, BS, 1962; MRCP.)

Mr J N Johnson Young doctors can make an important contribution to all aspects of the new GMC, particularly in matters concerning medical education. The Merrison Report emphasised the importance of electing young doctors to the GMC despite the difficulties "in getting the young to come forward to be elected." The report continued "we believe it essential to make special arrangements to ensure that young doctors.... stand for election to the General Council." The BMA is sponsoring eight junior doctors in England as candidates; I hope that all voters will cast some of their votes for doctors in this category. (Registrar in surgery, Liverpool; MB, ChB, 1970; FRCS.)

Dr S E Josse The GMC was set up to serve the public and the profession. There is now no excuse for the profession in the newly reconstituted GMC not to play its full part. My major interest lies in medical education and as regional adviser to North-east Thames RHA and as the newly appointed chairman of the Joint Committee for Postgraduate Training in General Practice I have been able to influence postgraduate education in the general practice field. I feel that my experience in medical education would be of some value to the GMC and I therefore offer myself for election. (General practitioner, London; MB, BS, 1956; FRCGP.)

Dr W P Kelly I suspect that most of you share my ignorance about the GMC. Its new image should reflect the views of the elected members but, like you, I suspect the establishment view will predominate. As I am not a GMSC or RCGP member, I consider I may be in a position to reflect "grass roots" opinion. I have a strictly orthodox medical background, with thirty years in general practice. I drifted into the LMC, talked too much, and was elected secretary. Astonishingly I was appointed to the $\operatorname{AHA}(\mathrm{T})$ and related committees. I submit that this has given me the necessary expertise. (General practitioner, Weston-super-Mare; MB, BChir, 1946.)

Dr L Kopelowitz The most exciting challenge for the new GMC will be the discharge of its educational responsibilities because medical education and the doctor's right to earn his livelihood are inextricably linked. In education the powers of the Council have been extended to embrace every stage in a doctor's life. It is therefore more important than ever before that the elected members should play a full part in determining the standards and educational policies of 
the medical profession. If elected, the presentation of the profession's point of view would be my prime concern. (General practitioner, Newcastle upon Tyne; MRCS, LRCP, 1951; MRCGP.)

Dr E B Lewis Over the last decade I have served on successive BMA subcommittees dealing with the GMC, TRAB, evidence to Merrison, and the subsequent Act. Given the opportunity to put our own house in order without Government interference, we must seize this chance to ensure that the new GMC both protects the patient and provides fair and compassionate treatment for the doctor and his family. I would claim to be experienced, tough, articulate, and fair. I seek to be a member of a well-balanced and highly experienced BMA team which will be needed to achieve the changes which are necessary. (Consultant anaesthetist, Ashford, Kent; MB, BChir, 1959; FFARCS.)

Dr A W Macara I can fairly claim to be a true hybrid practitioner/academic with experience of service, teaching, and research in health care locally, nationally, and internationally. Colleagues in Bristol and fellow members of the CCCM have persuaded me to stand for election because of my known concern to preserve traditional medical ethics while promoting the highest possible quality of personal service in the profession at this critical stage in our affairs. I am proud to be sponsored by the Association, which knows that I shall always try to do what seems right rather than expedient. (Consultant senior lecturer and honorary regional specialist in community medicine, Bristol; MB, ChB, 1958; FFCM.)

Mr T McFarlane The new GMC creates an opportunity for adequate representation of junior doctors. The stresses in the present system of medical training, both undergraduate and postgraduate, will be intensified by the expanding medical school output. As deputy chairman of the HJSC I will ensure that the views of doctors in training are voiced. Foreign doctors have many problems while training in this country and I am well placed to air their difficulties. Aspects of the disciplinary machinery-for example, the three wise men-need improving to be more fair in structure and operation. (Senior registrar in obstetrics and gynaecology, Manchester; MB, ChB, 1967; MRCOG.)

Dr John Marks I am deputy chairman of the Representative Body and of the GMSC. For nine years I have played a prominent part in the BMA's campaign for a reformed GMC with an elected majority. The new council must allow flexibility in undergraduate education and encourage the production of "community-orientated" doctors. It must use its new powers vigorously to promote higher standards of medical care. These, like postgraduate education, must not take second place to the NHS's requirements. If elected I will press for the rapid establishment of the health committee to prevent sick doctors hurting themselves and the public. (General practitioner, Boreham Wood; MB, ChB, 1948; FRCGP.)

\section{Dr W J Oldroyd}

I was active in an industrial town, in both single-handed practice and the local hospitals, for 20 years. My present full-time job as an LMC secretary brings me into contact with many doctors. Over the last eight years I have observed the dissatisfaction with the GMC leading to Merrison and the 1978 Medical Act. I believe the new structure proposed will work if the elected members truly reflect the high standards of the profession. My LMC work in Yorkshire and London has highlighted the problems regarding sick doctors. Elected members will require "nous" to make the GMC work. (Secretary, six London LMCs; MB, ChB, 1955; FRCGP.)
Dr F Pigott It may seem odd at first sight that an official of the BMA should offer himself for election. In my work I get a broad experience of the professional life and problems of doctors not confined to a particular specialty or area. My particular interests are providing help for doctors who who have become ill. Having served previously on the GMC and been active in campaigning for its reform, I hope that I will be able to take part in the work of the new council. (Provincial medical secretary, $B M A$, Cumbria ; $\mathrm{MB}, \mathrm{BS}, 1956$; FFARCS.)

\section{Professor I Rannie As a member of the working party} chaired by Sir Ronald Tunbridge I gained experience of the problems of the GMC. I welcomed the Merrison proposals. The resulting new GMC is perhaps large and unwieldy and it is important that the elected members should make sure that Merrison's proposals are implemented and not diluted by other interests. It is important that the views of the profession, as endorsed by the Representative Body of the BMA, should be adequately supported in the new GMC and if elected I would pursue that aim. (Professor of pathology and honorary consultant pathologist, Newcastle upon Tyne; MB, ChB, 1938; FRCPath.)

\section{Mr D L P Rees My aims would be: (1) to maintain} high standards of professional training, to introduce a more realistic career structure, with consultant expansion, to shorten specialist training with earlier entry to, and better organisation of, training programmes; (2) to require the council to monitor the effects of future underfunding of health care on training and on the profession's ability to discharge its skills; (3) to maintain high standards of professional conduct while allowing for changing social values; (4) to prevent increases in the retention fee, by increased administrative efficiency and by seeking alternative funding without compromising the council's independence. (Senior registrar in urological surgery, MB, BS, 1967; FRCS.)

Dr $\mathbf{M}$ Rees The presence of a junior hospital doctor on the GMC will make it more representative of the profession. It will help the GMC to keep in touch with the problems and needs of doctors in training. The 1978 Medical Act gave the GMC a new function to determine patterns of experience suitable for the preregistration year. I hope to help the GMC's Education Committee in its task of supervising the training of doctors in this important period of their career. I would also like to see the code of practice for the preregistration year more widely implemented. (Registrar in medicine, Sheffield; MB, ChB, 1976; MRCP.)

\section{Professor W Linford Rees Registration is inseparable} from medical education and the GMC must continue to improve the standards of undergraduate and postgraduate education. The behavioural sciences are essential in preclinical training. Clinical training must include social and psychological aspects of illness. High standards must be maintained in UK medical schools and in overseas medical schools seeking GMC recognition. The GMC's disciplinary functions are of fundamental importance to adequate standards of professional conduct. Where a doctor's behaviour may be due to ill health the case should be considered by a special committee. The GMC must be independent and alternative or supplementary funding should be considered. (Professor of psychiatry and honorary consultant psychiatrist, London; MB, BCh, 1943; FRCPsych.)

\section{Dr R B L Ridge My experience in general practice and} medicopolitics and my interest in the legal aspects of medicine will be relevant to the work of the council. In education, the curricula of the medical schools must 
afford a sound preparation for all forms of practice, and keep in step with the rapid advance of medical science. In assessing fitness to practice, in regard to both health and conduct, the decisions of the Council must be tempered with fairness, compassion, and awareness of a changing society. In financing its work the interest of the patients must be a charge on public funds. (General practitioner, Enfield; MB, BS, 1941.)

\section{Dr Sanjoy Roy-Chowdhury As someone who has relent- lessly campaigned for a} more representative GMC, I feel its primary role is to maintain the highest professional standards, though with a realistic sensitivity. As an elected CCHMS member and deputy chairman of a subcommittee, I know the problems of the so-called "sick doctor" and wish to bring a humane approach by healing the wound, as we would do to a patient. I am implicitly involved in overseas doctors' welfare and aware of their real problems, which will receive urgent attention. My vision is of a united and happy profession benevolently monitored by the new GMC. (Medical assistant, Blood Transfusion Service, London; MB, BS, 1956.)

\section{Professor D A Shaw The new GMC will require of its} members knowledge of the manifold activities and responsibilities of the profession and flexibility in face of changing undergraduate and postgraduate educational patterns, altering relationships with Europe, and as yet unrevealed Royal Commission recommendations. I volunteer my services on the basis of experience in the NHS as hospital practitioner and RHA member; in the BMA as member of the Northern Regional Council and the Newcastle Division, of which I am Chairman Elect; in medical education as teacher and associate dean; and, perhaps most importantly, from a deep concern for the future of British medicine. (Professor of clinical neurology and honorary consultant neurologist, Newcastle upon Tyne; MB, ChB, 1951; FRCP.)

\section{Dr I McKim Thompson}

I am Midlands provincial medical secretary of the BMA, covering the West Midlands and Trent Regions, which gives constant involvement in the day-to-day problems of doctors from all crafts, including those working in and out of the NHS. I have particular experience of younger doctors (national secretary Hospital Junior Staff Committee for the last nine years) and also of medical students (responsibility for BMA medical student activities). The main task for the GMC lies in the field of student numbers, the quality of the curriculum, the preregistration year, and the increasingly formalised postgraduate training programmes. (Provincial medical secretary, $B M A$, Birmingham; $\mathrm{MB}, \mathrm{ChB}, 1961$.

\section{Dr M A Thompson The regulation of the medical pro- fession is at last being conducted by} a GMC consisting of a majority of elected doctors and including the possibility of representation of younger doctors for the first time. This junior representation is essential if the revised council is to deal adequately with the problems of medical education including the preregistration year, the registration of overseas doctors, and the possible establishment of specialist registration. If elected to the General Medical Council I look forward to representing the views of junior doctors on these important issues. (Senior registrar in anaesthetics, London; MB, BS, 1970; FFARCS.)

\section{Mr A J Vallance-Owen}

I see being one of the youngest candidates in this election as a positive advantage. I was a medical student at Birmingham comparatively recently, where I was actively involved in the faculty and its committees. I am now going through my post- graduate training, while maintaining a critical interest in medical education, particularly methods of selection for medical school. I am working in a teaching hospital and I am a regional representative of the Hospital Junior Staff Committee. I believe my contacts with junior doctors and medical students would serve me well if I was elected to the GMC. (Registrar in general surgery, Newcastle upon Tyne; $\mathrm{MB}, \mathrm{ChB}, 1976$.

Dr C J Wells There is a new GMC with wider powers than at present. It has the general function of promoting high standards in and co-ordinating all stages of medical education. The Health Committee may direct suspension of or place conditions upon the registration of a practitioner whom it considers unfit to practise because of ill health. The Council is empowered to advise us on standards of professional conduct or medical ethics. All are matters of major importance to doctors and patients and I believe I can usefully contribute to Council's work in its formative years. (Retired general practitioner, Sheffield; MB, ChB, 1953; FRCGP.)

Dr (Frances) Mary White While active in the broad including the BMA Council and CCHMS, my interest is manpower, since this is fundamental to the profession's wellbeing. This includes staffing structure, the movement of doctors, and medical education as an ongoing procedure. With a present female medical intake of $38^{\circ}$, women may expect representation, but it should be as doctors not as women doctors. This does not deny special problems for some, with a need for training flexibility and career advice, but the strength of the political representation lies in considering the problems in the context of the whole medical profession. (General surgery, Worcester and Bromsgrove; MB, ChB, 1949; DObstRCOG.)

Mr D C Wilkins The new Medical Act and the Merrison Committee Report mean a much more democratic regulation of the medical profession. I am broadly sympathetic to the recommendations of the Merrison Committee and, if elected, would welcome the opportunity to help shape these before their implementation. In particular, I feel that the review of criteria for training of newly qualified doctors up to the stage of independent practice, though badly needed, requires careful thought if the whole system of registration and specialisation is not to be overbureaucratic and restrictive. (Senior registrar in surgery, London; MB, ChB, 1966; FRCS.)

Dr Lena Williams I offer 31 years' experience in general practice, giving administrative advice -having served with RAMC as DADMS of three divisions (BAOR 1944-7), and since 1963 working on the executive council and FPC. I have served with the LMC since 1951, and on DHSS appeals. As a Treasury and Admiralty medical officer in several boroughs I know the workings and requirements of government employees. I am basically against health centres but will help improve conditions if the Government persists in providing them. I sympathise with the many elderly singlehanded GPs, who should be helped. I am satisfied with and support the BMA's efforts. (General practitioner, London; MB, ChB, 1943.)

\section{Wales}

Dr M L Cattell The new constitution of the GMC should open the opportunity for the practising doctor to feel that he or she can influence its policies. There are increasingly rapid social changes impinging on our traditional values. I am fortunate in having a very wide experience of reflecting professional medical attitudes in Wales, derived from an extensive range of contacts in all branches of the profession. 
Being continuously acquainted with the problems of my colleagues on a daily basis, I wish to contribute to the effectiveness of the Welsh group on the GMC without sectional interest. (Welsh Secretary, BMA, Cardiff; MB, BCh, 1949.)

\section{Dr D J Llewellyn The GMC is not a medical parliament, as many people seem to think, but a} body constituted to administer the Medical Acts, which deal solely with registration, education, and professional discipline. I feel that it is important that Wales should have a general practitioner among its three representatives. As I have previously represented Wales for five years on the GMC, and also as postgraduate adviser in general practice for Wales, I believe that I have some worthwhile experience to offer the electorate. (General practitioner, Bridgend; MRCS, LRCP, 1956; FRCGP.)

\section{Mr R J Williams I believe in regulation of the profession} by the profession, particularly regarding maintenance of educational and professional standards. These are constantly threatened by erosion in a society whose attitudes and policies are changing so rapidly and radically. I would wish to see the GMC with increased elected medical membership become not only more sensitive to and representative of the profession as a whole but reinforced as a bulwark against political and other outside pressures and against political control of or encroachment on the standards, status, integrity, and independence of medicine. (Consultant surgeon, Cardiff; MB, BChir, 1944; FRCS.)

\section{Scotland}

Mr W Drummond

I was a member of Council of the Royal College of Surgeons of Edinburgh for many years, and of the Postgraduate Training Subcommittee of the CCHMS. I examined in Eire, Pakistan, Burma, and Hong Kong, participating in seminars there, and in Nepal, and it was gratifying to hear the frequently expressed wish for training in Britain. I have experience in negotiation, having served the Council, CCHMS, and several subcommittees. As regards ethical guidance, it is imperative that the highest standard of personal conduct and immaculate professional skill be observed at all times. (Retired consultant surgeon, Cupar; MB, ChB, 1936; FRCS.)

\section{Dr C D Falconer}

The connection between the GMC and the BMA Scottish Office has been a most practical arrangement as I know, since a BMA Scottish Secretary served on the GMC and the GMC's Scottish Branch Council met in the BMA's office. We gave BMA evidence on the Scottish interests in the GMC to the Royal Commission, and with a Scottish Assembly still in the background vigilance is needed. We must remain in full communication with what is taking place simultaneously in London and in Edinburgh and this I can do. There must be only one UK regulating body for our profession. (Scottish Secretary, BMA, Edinburgh; MB, ChB, 1939; FRCS.)

\section{Mr James Kyle}

The new GMC has the task of protecting the interests of the general public and the medical profession in a changing world. The high standards of British medicine must be maintained. The sick doctor should be treated in a humane and helpful manner, but the public must be safeguarded. The transition from the old GMC system to the new procedures will be difficult. It will be facilitated by having members elected who are already well versed in the problems of medical education, manpower planning, and complaints procedures, and who in their daily work see the difficulties confronting ordinary doctors. (Consultant surgeon, Aberdeen; MB, BCh, 1947; MCh.)

Dr A G R Law I am a general practitioner of nearly thirty years' standing. Through the BMA, LMC, and GMSC structures I have involved myself, for the greater part of this time, in matters pertaining to the welfare of my colleagues; at present I chair the Scottish General Medical Services Committee. I also have wide community interests and am a JP. Such experience is relevant to the two main functions of the new council, namely education and fitness to practise. I hope you will allow me to play a part in this new General Medical Council. (General practitioner, Dundee; MB, ChB, 1947; MRCGP.)

Dr G S McCune The new GMC should have among its members a wide representation of the medical profession. As a 33-year-old senior registrar in obstetrics and gynaecology, I stand to represent doctors in training. By virtue of my age I have more recent personal experience of some aspects of education than most of the current members. For the last four years I have served on BMA committees and in the NHS advisory structure and am a member of my specialty's subcommittees of the area medical committee and national medical consultative committee. I therefore have experience of the subjects dealt with by the GMC. (Senior registrar in obstetrics and gynaecology, Glasgow; MB, ChB, 1969; MRCOG.)

\section{Dr W Jeffrey C Scott}

The BMA has no chief whip to ensure that sponsored members of the GMC shall toe the party line. Rather should sponsorship be regarded as a way of ensuring that no branch of medicine is underrepresented. Yet even if all sponsored GPs are elected they will comprise only about 16 in a GMC of nearly 100 . My other interest is occupational medicine, which is the largest single group of doctors outside the NHS, and which has no other representation. As one of only three GPs in the present GMC, I urge all BMA members to support their sponsored candidates. (General practitioner, Alexandria; MB, ChB, 1946; MRCGP.)

\section{Northern Ireland}

Mr J Blundell The GMC has been undemocratic and has not reflected the profession's views. With the representation it should not abandon the principles which gave the profession the respect and confidence of the public. Doctors still hold special responsibilities and trust which must not be abused. The BMA is the only organisation capable of uniting all the profession's branches and members who take the trouble can have their views considered by the members whom they elect. It is, therefore, imperative to elect to the GMC BMA members whose priorities are the protection of the public and the whole profession. (Consultant surgeon, Newry; MB, BCh, 1949; FRCSIrel.)

\section{Mr D G C Whyte The medical profession should be self-} dent body. I regulated and controlled by an indepenservice and am in general practice before entering the hospital Northern Ireland Council; chairman, BMA Western Division; member, RCHMS, General Health Services Board, and Committee of Inquiry into Competence to Practise. This experience has provided insight into the requirements of consultants, medical assistants, GPs, community medicine doctors, overseas doctors, junior doctors, and women doctors. I support the highest standards of professional conduct. (Senior consultant radiologist, Londonderry; MB, BCh, 1937; FFRRCS.) 